\title{
Neuroimaging tools to rate regional atrophy, subcortical cerebrovascular disease, and regional cerebral blood flow and metabolism: consensus paper of the EADC
}

\author{
G B Frisoni, P h Scheltens, S Galluzzi, F M Nobili, N C Fox, P H Robert, H Soininen, L-O Wahlund, \\ G Waldemar, E Salmon
}

Neuroimaging is a mainstay in the differential diagnosis of patients with cognitive impairment. The often equivocal clinical pictures, the prognostic uncertainty of the earliest stages of mild cognitive impairment, and the subtle brain changes mean that neuroimaging techniques are of potentially great incremental diagnostic value. A number of methods, ranging from very simple subjective visual ratings to highly sophisticated computerised tools, have been developed, which allow rating of structural and functional brain changes. The choice of the method is not obvious, and current guidelines provide no indications on which tools should be preferred. In this paper, we give indications for tools with demonstrated accuracy for detecting regional atrophy, cerebrovascular disease, and regional brain function, and discuss these according to increasing technological complexity, ranging from those with high feasibility that can be used at the patient's bedside to highly technological ones that require trained personnel and specific hardware and software.

See end of article for authors' affiliations

Correspondence to: Dr G B Frisoni, Laboratory of Epidemiology \& Neuroimaging, IRCCS San Giovanni di Dio-FBF, via Pilastroni 4, 25125 Brescia, Italy; papers@centroalzheimer.it maging in dementia or cognitive impairment is moving from a negative, exclusionary role to one that adds positive diagnostic and prognostic information. Only 10 years ago, the practice parameters of the American Academy of Neurology regarded computed tomography (CT) and magnetic resonance (MR) as "optional" examinations. ${ }^{1}$ The belief is now widely held that quantitative ratings of structural and functional changes can have an impact on the clinical management of the patient. ${ }^{2}$

The increased social awareness of cognitive disturbances brings patients to first medical observation in earlier stages of the dementing disorder, ${ }^{3}{ }^{4}$ when the diagnosis is often uncertain and imaging can represent a significant aid to the differential diagnosis. Hippocampal atrophy on $\mathrm{MR}^{5}{ }^{5}$ and medial temporal or temporoparietal cortical hypoperfusion/hypometabolism on single photon emission tomography (SPET) $)^{67}$ and positron emission tomography $(\mathrm{PET})^{8}$ have been shown to be among the most accurate markers of conversion of patients with mild cognitive impairment (MCI) to Alzheimer's disease (AD).
Furthermore, the rate of atrophy progression has been suggested as a feasible surrogate marker for trials of disease modifying drugs, ${ }^{9}$ and indeed, atrophy measures have now been adopted in several current trials in MCI and $\mathrm{AD} .^{10}$

Available criteria for vascular dementia ${ }^{11}{ }^{12}$ require brain imaging criteria that define minimum extension, topography, and severity of vascular lesions. In the NINDS-AIREN criteria, leukoencephalopathy involving at least $25 \%$ of the total white matter must be present to diagnose small vessel cerebrovascular disease. Tools to rate quantitatively the vascular load in the brain might increase the diagnostic accuracy of vascular dementia.

The practising dementia specialist can find few literature indications on how to exploit the potential of neuroimaging. Diagnostic guidelines issued by the European Federation of Neurological Societies ${ }^{13}$ and the more recently issued practice parameters of the American Academy of Neurology ${ }^{14}$ suggest that at least one structural CT or MR examination should be made over the course of a dementing disorder to rule out space occupying or vascular lesions, and that SPET and PET should be used in cases of significant diagnostic uncertainty. Moreover, they suggest that, although not required by guidelines, more specific CT/MR parameters measuring atrophy and subcortical vascular lesions and SPECT/PET parameters of perfusion/metabolism may be diagnostic aids in the evaluation of patients with cognitive impairment. However, no indication is provided as to how images should be rated to extract clinically useful information.

Paradoxically, scores of methods to rate structural and functional changes in the brains of patients with cognitive impairment can be found in the literature. ${ }^{15}$ Methods range from very simple subjective visual ratings to highly sophisticated computerised tools. The choice of the method is not obvious. The diagnostic accuracy (sensitivity and specificity) generally

Abbreviations: $A D$, Alzheimer's disease; ARWMC, Age Related White Matter Changes; CT, computed tomography; $\mathrm{MCl}$, mild cognitive impairment; $M R$, magnetic resonance; MTL, medial temporal lobe; MMS Mini Mental State; PET, positron emission tomography; SPET, single photon emission tomography 
Table 1 Levels of increasing technological intensity of tools to rate structural imaging findings in patients with cognitive impairment

\begin{tabular}{|c|c|c|c|c|c|c|}
\hline \multirow[b]{2}{*}{ Level } & \multirow[b]{2}{*}{ Medium } & \multirow[b]{2}{*}{ Technical requirements } & \multicolumn{2}{|l|}{ Regional atrophy } & \multicolumn{2}{|c|}{ Subcortical cerebrovascular disease } \\
\hline & & & Measurement & Experience & Measurement & Experience \\
\hline CT 1 & Film & Routine acquisition* & None & - & $\begin{array}{l}\text { Visual rating scales: ARWMC } \\
\text { scale }^{21}\end{array}$ & $1-2$ weeks \\
\hline CT 2 & Film & $\begin{array}{l}\text { 2-3 mm thick slices on } \\
\text { temporal lobe plane }\end{array}$ & $\begin{array}{l}\text { Linear measures: minimum } \\
\text { thickness of the } \mathrm{MTL}^{22} \text { and radial } \\
\text { width of the temporal horn }\end{array}$ & $1-3$ days & None & - \\
\hline MR 1 & Film & Routine acquisition $†$ & $\begin{array}{l}\text { Visual rating scales: Scheltens' } \\
\text { MTL atrophy score } \\
\text { Linear measures: width of the } \\
\text { temporal horn } \\
\text { te }^{30}\end{array}$ & $\begin{array}{l}1-3 \text { days } \\
1-3 \text { days }\end{array}$ & $\begin{array}{l}\text { Visual rating scales: ARWMC } \\
\text { scale }^{21}\end{array}$ & $1-2$ weeks \\
\hline MR 2 & Digital & $\begin{array}{l}\text { 3D T1 acquisition manual } \\
\text { or semiautomatic post- } \\
\text { processing }\end{array}$ & $\begin{array}{l}\text { Volumetric measures: } \\
\text { hippocampal and entorhinal } \\
\text { cortex volumes }^{38} 39\end{array}$ & $2-4$ weeks & $\begin{array}{l}\text { Volumetric measures: } \\
\text { thresholding of } \mathrm{WMH}^{41}\end{array}$ & 1 day \\
\hline MR 3 & Digital & $\begin{array}{l}\text { 3D T1 acquisition software } \\
\text { for computerised post- } \\
\text { processing serial scans }\end{array}$ & $\begin{array}{l}\text { Prospective whole brain } \\
\text { assessment: brain boundary shift } \\
\text { integral }^{45}\end{array}$ & - & None & - \\
\hline
\end{tabular}

ARWMC, Age Related White Matter Changes; MTL, medial temporal lobe; WMH, white matter hyperintensities; ROI, region of interest.

*Orbitomeatal line, slice thickness of 8-10 mm; tincluding coronal T1 acquisition through the MTL.

Experience denotes the training time needed to obtain accurate measurements.

ranges between 70 and $90 \%{ }^{15}{ }^{16}$ and, although it is likely that more sophisticated methods are more accurate, there is little evidence that this is the case. Moreover, the accuracy of any method is heavily affected by personal expertise and clinical composition of the population of interest, and the incremental diagnostic accuracy by number and type of other diagnostic tests. Thus, as is often the case in medicine, ${ }^{17}$ the dementia specialist will choose more on the basis of practical considerations (availability, accessibility, cost, technical feasibility) than strict scientific evidence.

The aim of this paper is to highlight those instruments that the practising dementia specialist might use in the clinical setting. The paper is a consensus produced by the Neuroimaging Working Group of the European Alzheimer's Disease Consortium (EADC). The EADC is a consortium of 43 Alzheimer's centres in 13 European countries (principal investigator Pr. B Vellas, Toulouse, France, www.alzheimer-europe.org/EADC), and is funded by the European Union with the purpose of defining operational standards of excellence for the diagnosis and treatment of patients with cognitive impairment. The first draft of the consensus was produced on 12 November 2001, in Toulouse, France, during one of the biannual meetings of the EADC. The first draft of the manuscript was produced in July 2002 and circulated for comments to all EADC centres, as was the final version.

The instruments have been selected by capitalising on the experience of previous reviews made by some of the authors. ${ }^{15}{ }^{18-20}$ The instruments will be described according to increasing levels of technological complexity and feasibility so that physicians can choose those more consistent with the technological facilities of their clinical setting. Levels range from unaided ratings (subjective visual) of films or hard copies obtained with routine acquisition protocols on a single occasion to sophisticated computer based measurements based on digital images obtained with non-routine specific acquisition protocols on two or more separate occasions (tables 1 and 2). The variables of interest will be the three main aspects in the assessment of cognitive disturbances, i.e. regional atrophy, subcortical cerebrovascular disease, and regional functional (perfusion/metabolism) defects. CT and MR will be addressed separately because generally different tools apply to the two techniques, while SPET and PET will be addressed together as the same tools can be used and the two techniques give grossly similar clinical information.

\section{CT LEVEL 1: FILM WITH ROUTINE ACQUISITION (ORBITOMEATAL LINE, SLICE THICKNESS 8-10 MM)} Subcortical cerebrovascular disease: visual rating scales A number of rating scales to grade subcortical cerebrovascular disease (SCVD) on CT or MR films have been developed. ${ }^{18}$ The European Task Force on Age Related White Matter Changes reviewed instruments developed as of 1998, and concluded that the ideal rating scale did not yet exist. $^{18}$ Based on this conclusion, they developed an instrument to rate SCVD, which was applicable to routine axial CT scans (the Age Related White Matter Changes (ARWMC) scale). ${ }^{21}$ This is a four-point scale that rates white matter changes separately in five areas: frontal, parieto-occipital, temporal, infratentorial/cerebellum, and basal ganglia (striatum, globus pallidus, thalamus, internal/external capsule, and insula). The first three areas are scored as $0=$ no lesions (including symmetrical, well defined caps or bands), $1=$ focal lesions, 2 = beginning confluence of lesions, $3=$ diffuse

Table 2 Levels of increasing technological intensity of tools to rate functional imaging findings in patients with cognitive impairment

\begin{tabular}{|c|c|c|c|c|}
\hline \multirow[b]{2}{*}{ Level } & \multirow[b]{2}{*}{ Medium } & \multirow[b]{2}{*}{ Technical requirements } & \multicolumn{2}{|l|}{ Focal hypoperfusion/metabolism } \\
\hline & & & Measurement & Experience \\
\hline SPET/PET 1 & Hardcopy & - & Visual assessment & $1-2$ weeks \\
\hline SPET/PET 2 & Digital & - & ROI sampling & $1-3$ days \\
\hline SPET/PET 3 & Digital & Software for computerised post-processing & Voxel by voxel analysis in the stereotactic space ${ }^{61}$ & - \\
\hline
\end{tabular}

$\mathrm{ROI}$, region of interest.

Experience denotes the training time needed to obtain accurate measurements. 


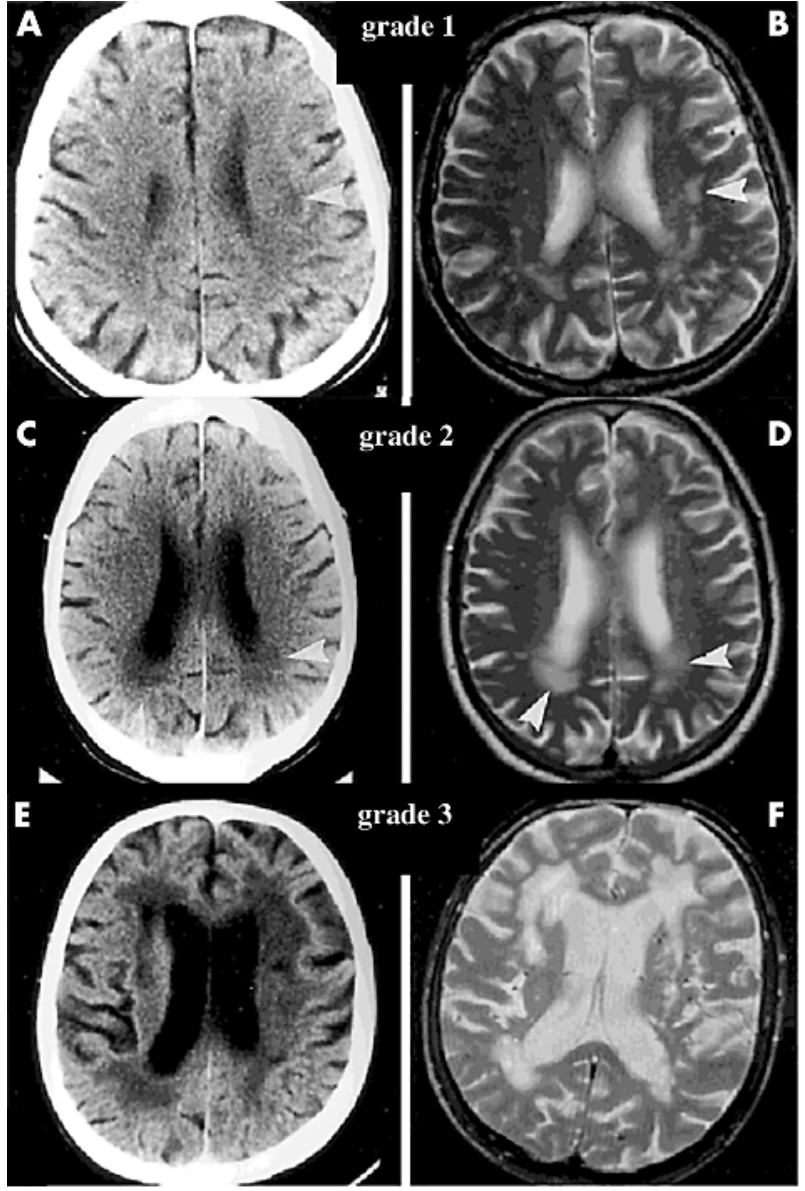

Figure 1 CT level 1 (left side images) and MR level 1 (right side images) for cerebrovascular disease: a visual rating scale based on CT and MR films (the Age Related White Matter Changes scale ${ }^{21}$ ). Grade 1, focal lesions; grade 2, early beginning confluent lesions; grade 3 , confluent lesions with diffuse involvement of a lobe, with or without involvement of $U$ fibress. Image pairs (CT/MR) are matching slices of the same patient. Reprinted with permission from American Heart Association.

involvement of the entire region, with or without involvement of $U$ fibres. The infratentorial/cerebellum and basal ganglia are scored as $0=$ no lesions, $1=$ only one focal lesion $(>5 \mathrm{~mm}), 2=$ more than one focal lesion, $3=$ confluent lesions. The final result of the rating is 10 separate scores (five for the right and five for the left hemisphere) ranging between 0 and 3, rating the different brain regions (fig 1 ).

The inter-rater reliability was found to be moderate $(\mathrm{k}=0.48)$. The ARWMC scale was applied on both CT and MR films. A good correlation between the two imaging modalities was found; in more than $50 \%$ of patients CT and MR scored equal in all areas. However, in $31 \%$ of patients MR scored parieto-occipital lesions better than CT, and scored infratentorial lesions better in $23 \%$ of patients. The clinical features of the 77 patients with white matter changes used to validate the ARWMC scale were not described, and data on known group validity were not reported.

The novelty of the ARWMC scale is that images due to different pathology such as lacunes (featuring axonal loss) and white matter lesions (featuring demyelination with little or no axonal loss) are rated separately. The main limitation is represented by the unavailability of a global measurement of severity, as the sum score of the 10 ratings has not yet been validated. There are no data on the added diagnostic value of this scale.

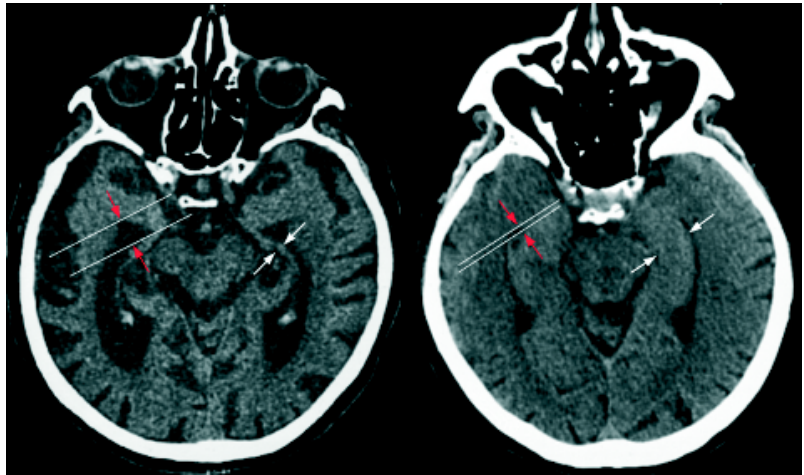

Figure $2 \mathrm{CT}$ level 2 for regional atrophy: linear measurements of medial temporal lobe atrophy based on CT films. Minimum thickness of the medial temporal lobe ${ }^{22}$ : the measurement is taken in the parahippocampal gyrus region where the portion between the anterior and posterior aspects of the brainstem is thinnest (white arrows). Radial width of the temporal horn ${ }^{27}$ : the measurement is the distance between two parallel lines drawn tangential to the tip of the temporal horns where its width is maximum (red arrows). Right side, non-demented elderly person; left side: Alzheimer's disease.

\section{CT LEVEL 2: FILM WITH 2-3 MM THICK SLICES ON THE TEMPORAL LOBE PLANE}

\section{Regional atrophy: linear measures}

Atrophy in the medial temporal lobe (MTL) is usually not obvious on CT films because the scan angle routinely used does not give the best image of this region. ${ }^{22}$ However, with a different scan angle (slice orientation parallel to the plane of the temporal lobe, i.e. $15-20^{\circ}$ caudal to the infraorbitomeatal line), ${ }^{23}$ atrophy of the MTL can be detected with linear measures in $\mathrm{AD}$ patients.

The minimum thickness of the MTL is the most widely recognised linear CT measurement. ${ }^{22}$ The technical requirements for this measurement are the orientation of the CT scan parallel to the plan of the temporal lobe and thin slice thickness $(2-3 \mathrm{~mm})$. The measurement is taken with a calliper in the parahippocampal gyrus region, where the portion between the anterior and posterior aspects of the brainstem is thinnest (fig 2 ). In a group of 44 pathologically confirmed AD patients with mean (SD) Mini Mental State (MMS) scores of 9.3 (6.9), Jobst et al found that the minimum thickness of the MTL separated AD patients from non-demented controls with a sensitivity of $92 \%$ and specificity of $95 \%$. Two recent studies of mild AD patients found lower sensitivity values: $48 \%$ in 33 patients with MMS of 22 (2.1) compared with 31 controls, ${ }^{24}$ and $75 \%$ (specificity $90 \%$ ) in 60 with MMS of 19.6 (4.5) $v 17$ patients with vascular dementia, 14 with depression and nine with paraphrenia. ${ }^{25}$ Jobst et al showed that the progression of MTL atrophy thus measured was a sensitive marker of incident cognitive deterioration in subjects who were cognitively normal at baseline. ${ }^{26}$

Recently, a CT based measurement of MTL atrophy has been developed based on enlargement of radial width of the temporal horn. ${ }^{27}$ The measurement is sufficiently reliable, accurate, and feasible to be routinely employed..$^{27}$ CT scans are acquired according to the technique of Jobst et al, and the measurement can be taken also on MR scans. As the greatest proportion of hippocampal atrophy typical of $\mathrm{AD}$ takes place in the hippocampal head, ${ }^{28}$ the radial width of the temporal horn measurement is devised so as to capture atrophy in this region. The measurement is taken at the tip of the temporal horn with a precision calliper (fig 2). Intraclass correlation coefficients for inter- and intra-rater reliability were between 0.94 and 0.98 . Using a cutoff of $5.3 \mathrm{~mm}$, the sensitivity and 
specificity were 93 and $97 \%$ in separating 42 mild to moderate AD patients (MMS of 21 (2.3)) from 29 nondemented controls. In a small group of patients with mild cognitive impairment, the measurement has been shown to have sensitivity and specificity of 80 and $95 \%{ }^{29}$ There are no data on the added diagnostic value of these measurements.

\section{MR LEVEL 1: FILM WITH ROUTINE ACQUISITION (ROUTINE T2 AXIAL, ROUTINE TI CORONAL THROUGH THE MEDIAL TEMPORAL LOBE) Regional atrophy: visual rating scales and linear measurements}

While CT imaging of the temporal lobe allows appreciation of the indirect signs of hippocampal atrophy (such as the enlargement of the temporal horns), MR can directly visualise the hippocampus and other critical MTL structure in substantial cytoarchitectonic detail. Scheltens et $a^{30}$ have developed a subjective visual rating scale to assess MTL atrophy on plain MR films (the subjective MTL atrophy score). Tl weighted sequences are used and six coronal slices (slice thickness of $5 \mathrm{~mm}$ ) parallel to the brainstem axis are acquired from a midsagittal scout image, the first image being acquired directly adjacent to the brainstem. The score is assigned based on visual rating of the width of the choroid fissure, width of the temporal horn, and height of the hippocampal formation. The resulting scores are $0=$ absent, $1=$ minimal, $2=$ mild, $3=$ moderate, and $4=$ severe MTL atrophy (fig 3A).

In $21 \mathrm{AD}$ patients and 21 controls, the subjective MTL atrophy score yielded a sensitivity of $81 \%$ and specificity of $67 \%$. The score correlated well with linear measurements of MTL atrophy. ${ }^{31}$ Moreover, in 41 patients with AD and 66 nondemented controls, the subjective MTL atrophy score showed a correct classification of $96 \%$, slightly higher than the correct classification given by volumetry $(93 \%) .{ }^{31}$ In the same study, visual rating yielded a diagnostic gain over the mini-mental state examination (MMSE) score alone, while volumetry did not. ${ }^{31}$ Lastly, in a prospective study of 31 patients with minor cognitive impairment, the subjective MTL atrophy score and hippocampal volume improved the predictive accuracy of age and delayed recall score for $\mathrm{AD}$ at follow up. ${ }^{32}$ Although the overall predictive accuracy of hippocampal volume measurement was better than that of the score (100\% $v 83 \%)$, qualitative rating was suggested as a good alternative. ${ }^{32}$

The sensitivity and specificity of linear measurements of the width of the temporal horn were investigated on coronal MR films where the measurements were taken according to a standard method (fig 3B)..$^{24}$ In $46 \mathrm{AD}$ patients and 31 controls, the width of the temporal horn had a sensitivity of $74 \%$ in mildly and $82 \%$ in moderately severe AD patients with specificity set at $95 \%{ }^{24}$

\section{Subcortical cerebrovascular disease: visual rating scales}

When the ARWMC scale is applied on MR films, acquisition is made by routine axial T2 weighted or (preferably) fluid attenuated inversion recovery (FLAIR) sequences. Lesions are rated similarly to CT (fig 1). The inter-rater reliability on MR was good $(\mathrm{k}=0.67)$. The scale was validated comparing the degree and distribution of white matter changes on CT and MR films in the different areas. MR was superior for detecting small white matter changes, whereas larger lesions were detected equally well with both CT and MR. MR detected significantly more white matter changes than did CT in the parieto-occipital and infratentorial areas. ${ }^{21}$

Although the ARWMC scale is a reliable tool to quantify sCVD on both CT and MR films, whether the CT or the MR version should be preferred for clinical applications still needs
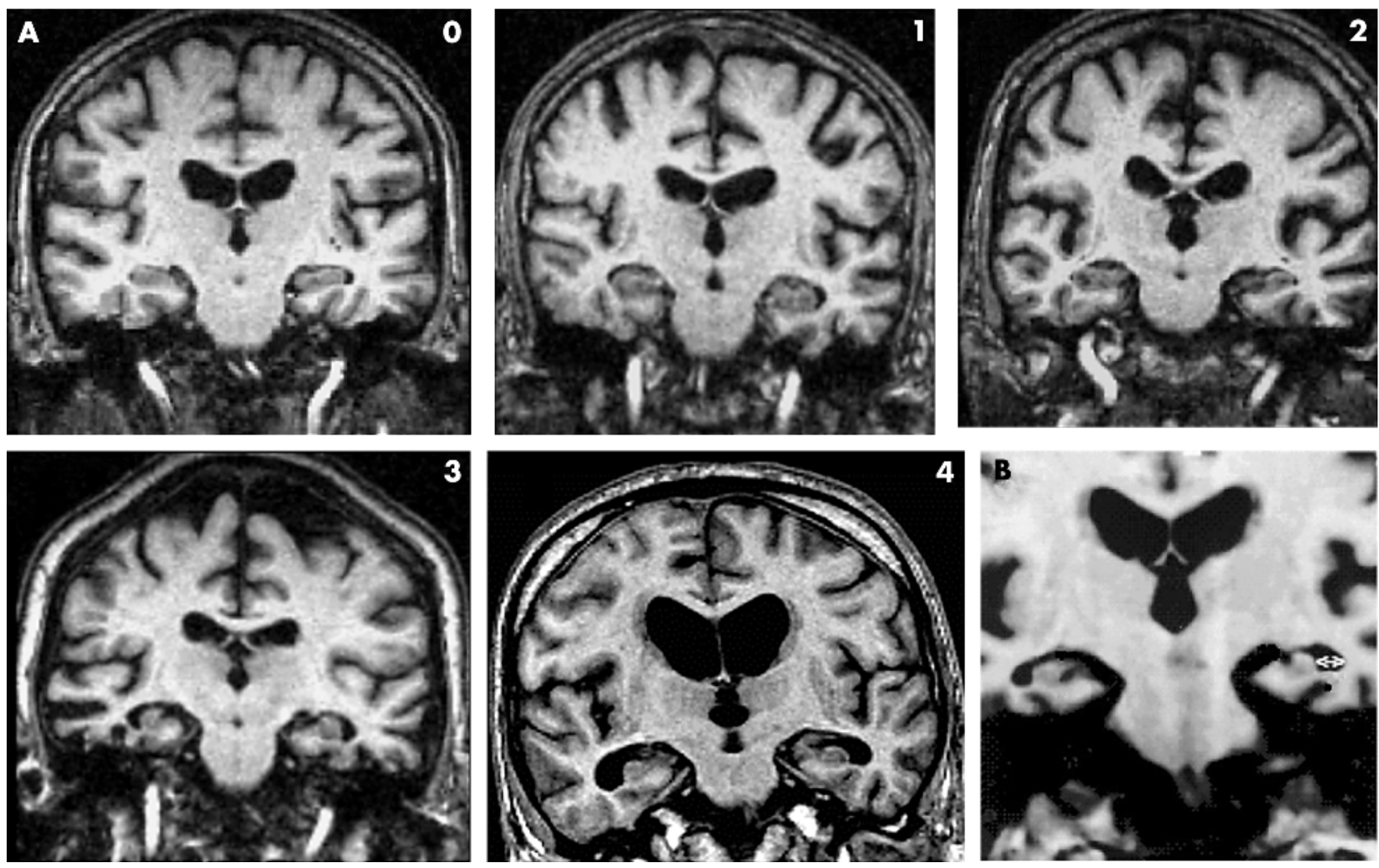

Figure 3 MR level 1 for regional atrophy: visual rating and linear measurements of the medial temporal lobe atrophy based on MR films. (A) subjective medial temporal lobe atrophy score: $0=$ absent, $1=$ minimal, $2=$ mild, $3=$ moderate, and $4=$ severe. ${ }^{30}(B)$ Width of the temporal horn. ${ }^{24}$ 
to be determined. While MR is more sensitive than CT, the latter might be preferred in clinical practice for its greater specificity in order to reduce false positives. ${ }^{33-35}$ Studies are needed to compare the CT and MR based versions of the ARWMC scale. There are no data on the added diagnostic value of either the CT or MR based version of this scale.

\section{MR LEVEL 2: DIGITAL WITH 3D ACQUISITION AND MANUAL OR SEMIAUTOMATIC POST-PROCESSING Regional atrophy: volumetric measurements}

The need for biological indicators of $\mathrm{AD}$ with high sensitivity and specificity is of great importance in pre-dementia forms of $\mathrm{AD}$ (MCI), where the clinical picture is less distinctive, the clinical diagnosis more difficult, and biological markers of the disease might yield significant incremental diagnostic value. ${ }^{36}$ Although there are yet no studies assessing the accuracy of different techniques in the diagnosis of MCI due to $\mathrm{AD}$, it is likely that MR levels 2 and 3 might be particularly useful. ${ }^{37}$

Some protocols of hippocampal volume measurement have been validated. ${ }^{38}{ }^{39}$ A Tl weighted 3D technique is employed for MR image (acquisition magnetisation prepared rapid acquisition gradient echo, MP-RAGE; or spoiled gradient recalled). After acquisition of the MR scans, the digital data must be available for post-processing. Images need to be reconstructed on coronal, $1-2 \mathrm{~mm}$ thick slices perpendicular to the orbitomeatal line or to the long axis of the hippocampus. The hippocampus is then manually traced on all the contiguous slices where it can be seen (fig 4A). Volumes are calculated in $\mathrm{mm}^{3}$ by computing the number of voxels within the traced images.

In expert hands, the reliability is high, intraclass correlation coefficients for hippocampal measurements being 0.95 for intra-rater and 0.90 for inter-rater variability. ${ }^{39}$ Sensitivity and specificity values of hippocampal volumes in a relatively large series of 55 mild $\mathrm{AD}$ patients and 42 controls were 94 and $90 \%$, respectively. ${ }^{40}$ Small hippocampal volume has been found to be predictive of subsequent conversion to $\mathrm{AD}$ in 80 patients with amnestic MCI independently of neuropsychological tests, apolipoprotein E genotype, and cerebrovascular comorbidity. ${ }^{5}$ Of the 13 MCI patients with hippocampal volume 2.5 SDs below the age specific mean, six (46\%) converted to $\mathrm{AD}$ within the following 3 years; of the 54 with hippocampal volume between the mean and 2.5 SDs below, there were 19 converters (35\%); and of the 13 with hippocampal volume above the mean, only two (15\%) converted.

The incremental value of hippocampal volumetry in the differential diagnosis between $\mathrm{AD}$ and other dementias has been addressed by Wahlund et al in a small patient group $(\mathrm{n}=77)$ with a stereological technique, a simplified version of manual tracing, ${ }^{31}$ and compared with visual rating of the medial temporal lobe. The authors found that the correct classification rate of the MMSE alone (63\%) was increased by both techniques (volumetry, 73\%; visual rating, $71 \%$ ).

\section{Subcortical cerebrovascular disease: thresholding of white matter hyperintensities}

Quantification of the volume of white matter hyperintensities (WMH) based on MR can provide an objective measurement of the severity of sCVD.

A number of semi-automated methods have been developed, most based on the notion that pixels of normal white matter can be accurately separated from those of hyperintense white matter. One of the first methods was developed at the National Institute of Health by DeCarli et $a l^{41}$ (QUANTA) but many others have followed. ${ }^{42}$ A conventional spin echo, double echo T2 or FLAIR sequence in the axial orientation is used for MR acquisition. Optimal results are obtained with scanners with field power of at least 1.0 Tesla.

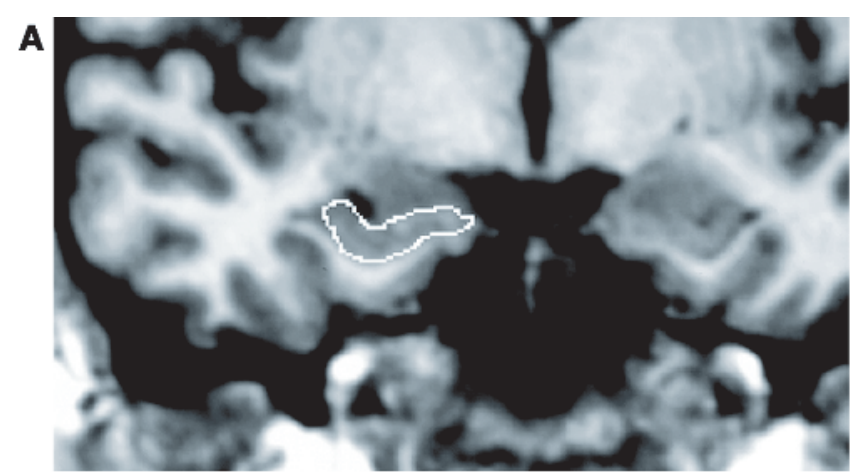

Figure 4 MR level 2 for (A) regional atrophy; volumetrics of the hippocampus based on digital MR. ${ }^{38}{ }^{39}$ Example of manual tracing; (B) Cerebrovascular disease: thresholding of white matter hyperintensities (WMH) based on digital $M R{ }^{41}$ example of distribution intensity of pixels on MR. Thresholding techniques automatically identify the value of pixel intensity that best separates normal white matter (WM) from WMH.

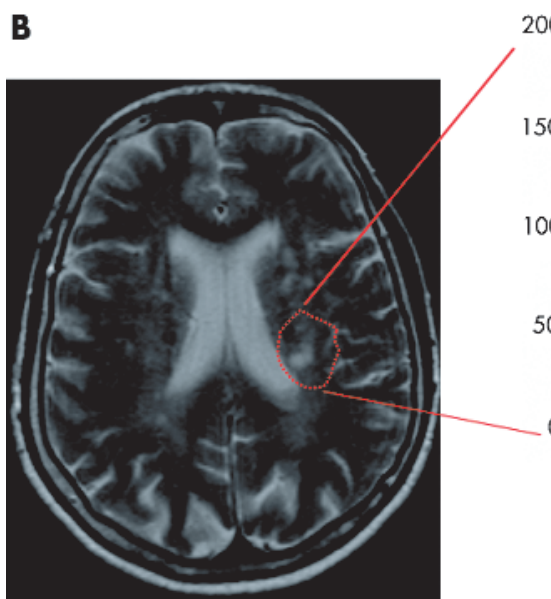


Digital information is generally transferred for processing and analysis to a separate workstation. Measuring involves manual tracing followed by automatic thresholding. Manual tracing is carried out on a crudely defined region of interest (ROI) within the white matter, which completely includes all the hyperintense white matter. Automatic segmentation comprises the following phases: histogram representation of the pixel intensity distribution, Gaussian modelling of the pixel distribution separately for normal and hyperintense white matter, and identification of the optimal intensity cutoff to separate normal from hyperintense white matter pixels on the basis of maximum likelihood functions (fig 4B). WMH volumes are computed in $\mathrm{cm}^{3}$ by multiplying the number of pixels assigned to hyperintense white matter in all the pertinent slices by the pixel volume. More automated techniques have also been developed..$^{43}$

Intra- and inter-rater reliabilities of this method are good. ${ }^{41}$ WMH volume has been found to correlate with other features believed to be indicative of SCVD (parkinsonism and depression) and was predictive of cognitive impairment in a group of 369 cognitively intact community dwelling older men. ${ }^{44}$ There are no data on the added diagnostic value of this tool.

\section{MR LEVEL 3: DIGITAL WITH 3D ACQUISITION, COMPUTERISED POST-PROCESSING, AND SERIAL SCANS \\ Regional atrophy: whole brain assessment with the brain boundary shift integral}

Serial scans within the same subject have the advantage that the wide inter-individual variability of brain morphology is not an issue, and comparing before and after images of the same subject(s) carries much less error than comparing a case with controls. Although the method is not available for clinical use, its potential clinical applications are such that the practising physician should be aware of its existence.

According to the brain boundary shift integral (BBSI) algorithm developed by Fox and Freeborough, ${ }^{45}$ serial (at least two) Tl weighted volumetric MR scans need to be acquired with a 3D technique as described in MR level 2 . Serial scans are positionally matched so that differences in the two scans can be visualised by subtracting one scan from the other (fig 5). An automated subtraction algorithm is then used to measure the difference in brain volume. Brain volume changes are measured by calculating the integral of the shift in the brain-cerebrospinal fluid boundary taken over

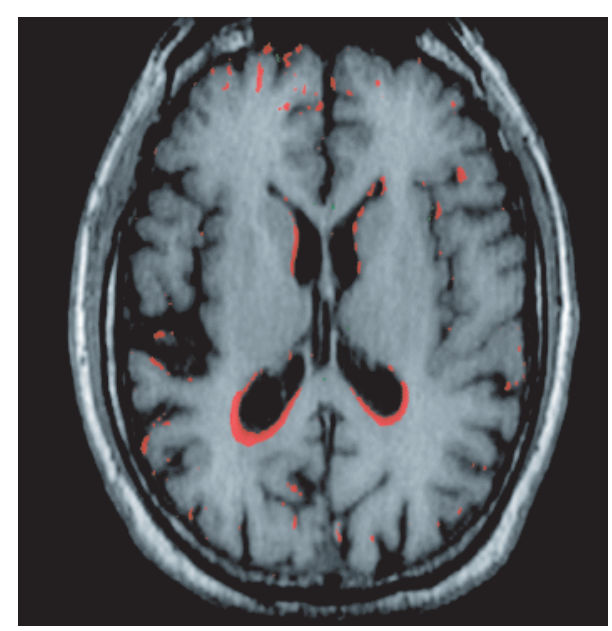

Figure 5 MR level 3 for regional atrophy: Fox and Freeborough's brain boundary shift integral (BBSI) based on digital MR ${ }^{45}$ greater than normal loss of atrophy over 1 year in a patient with $A D$ (voxels marked in red). the brain surface. Volume loss is expressed as a percentage of initial brain volume and converted into a rate of atrophy in $\mathrm{cm}^{3}$ per year.

The reproducibility of this technique is good: the mean coefficients of variation of brain volumes for inter- and intra-rater reproducibility were $0.55 \%$ (range $0.07-1.1 \%$ ) and $0.54 \%$ (range $0.03-1.5 \%) .{ }^{46}$ The rate of atrophy in a group of $18 \mathrm{AD}$ patients was significantly greater than in 31 controls $(2.78 \% \mathrm{v}$ $0.24 \%$ per year with no overlap between the groups). ${ }^{47}$ Moreover, the rate of global cerebral volume loss was strongly correlated with the rate of cognitive change measured with the MMSE in 29 AD patients. ${ }^{48}$ Although there are no explicit data on the added diagnostic value of the technique, the method allowed detection of loss of brain tissue in asymptomatic individuals carrying an autosomal dominant mutation known to cause $\mathrm{AD}$ more than 2 years before the appearance of symptoms. ${ }^{49} 50$

Although the use of the BBSI in MCI patients to predict conversion to $\mathrm{AD}$ is tempting, the need for prospective scans spaced at least 1 year apart and the high conversion rate in some clinical series (up to $25 \%$ per year) might lead to a significant proportion of converters by the time the test is positive. The technique might be more useful in truly asymptomatic persons at high risk for $\mathrm{AD}$, who might have first year conversion rates close to zero, such as apoE 4/4 carriers or APP or presenilin mutation carriers. In four persons coming from families with early onset $\mathrm{AD}$ resulting from known autosomal dominant mutations (APP V717G, PS1 M139V, and PS1 intron 4), the technique was shown to be sensitive to the volumetric reduction of the brain parenchyma more than 1 year before the onset of the mildest symptoms and about 4 years before the patient fulfilled criteria for $\mathrm{AD} .{ }^{50}$

\section{SPET/PET LEVEL 1: HARDCOPY}

\section{Visual assessment}

Measurements of regional blood flow with SPET and of regional glucose metabolism with PET can detect cerebral functional impairment at the cellular level and complement information on structural changes obtained by structural imaging methods in the evaluation of dementia. ${ }^{51} 14$ In conditions where a normal coupling of metabolism and perfusion can be expected, SPET can provide data reasonably comparable to those of PET with significant cost savings. ${ }^{52}$

For ${ }^{18}$ FDG-PET, the subject should be studied in the fasted state, and a minimum of 30 min to allow brain accumulation of the radiotracer is recommended. Other requirements (injected dose, scanning time, reconstruction, position) depend on the machine and the acquisition mode. Conditions of examination should be kept constant to allow comparison between local normative and patient data.

The currently used analysis method in most nuclear medicine departments is that of subjective visual assessment of SPET/PET colour coded hardcopies, showing in AD a typical pattern of temporoparietal hypoperfusion/hypometabolism (fig 6), although frontal defects are also very common even in the early stage..$^{53}$

A clinical pathological study $y^{54}$ evaluated the sensitivity and specificity of the visual assessment of SPET in 70 patients with dementia and 70 controls. Sagittal, coronal, and axial SPET orientations were evaluated by experienced personnel and rated as normal or abnormal (hypoperfused) in the lobar region, cerebellum, and subcortical structures in each hemisphere. Criteria for the presence of $\mathrm{AD}$ were previously agreed upon to include either bilateral or asymmetric temporal or parietal lobe hypoperfusion, or both. SPET significantly improved the diagnostic accuracy of $\mathrm{AD}$; a positive SPET scan raised the likelihood of pathological $\mathrm{AD}$ from $84 \%$, as defined by clinical diagnosis, to $92 \%$. Few studies included 


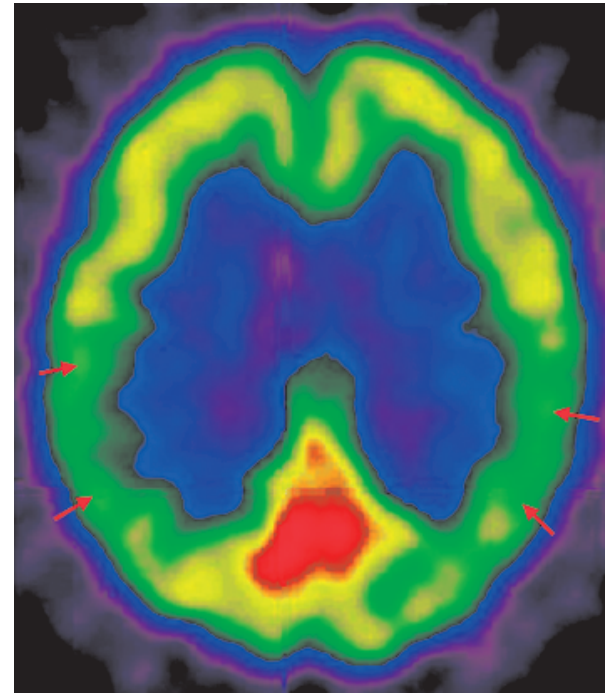

Figure 6 SPET/PET level 1: visual assessment based on SPET/PET hardcopy: ${ }^{18} \mathrm{FDG}$-PET hardcopy, showing in AD a typical pattern of bilateral parietal hypometabolism (arrows).

both MRI/CT and SPECT and compared diagnostic utility or added value. ${ }^{55}{ }^{56}$ The study by Scheltens et $a l^{57}$ in a population based sample concluded that SPECT did not have an added value over MRI.

The sensitivity and specificity of the visual assessment of PET has recently been evaluated in 284 patients with dementia, 146 of whom had a 2 year follow up and 138 had pathological confirmation. ${ }^{58}$ PET films were classified by criteria established beforehand as positive or negative for presence of $\mathrm{AD}$. The inter-rater reliability was good: assigned PET classifications were concordant in $94 \%$ of cases. PET identified patients with neuropathologically based $\mathrm{AD}$ with a sensitivity of $94 \%$ and a specificity of $73 \%$. The initial pattern of cerebral metabolism was significantly associated with the subsequent progression of cognitive impairment. The results were similar for questionable and mild dementia. For this group, sensitivity and specificity values were $95 \%$ and $71 \%$ respectively, with overall accuracy of $89 \%$, that is, as high as for the whole group.

As these figures of diagnostic accuracy are not significantly higher than those achieved with clinical assessment plus structural imaging, current guidelines recommend SPET/PET and visual assessment in selected cases where diagnostic uncertainty is relevant and the examination can provide significant incremental information. ${ }^{13} 14$

\section{SPET/PET LEVEL 2: DIGITAL WITH REGION OF INTEREST SAMPLING}

The semiautomatic assessment of brain perfusion and metabolism deficits is a quantitative approach. With PET, models are available to obtain absolute values of cerebral blood flow (CBF) or metabolic rates of oxygen or glucose consumption, to be compared to normative data. Alternatively, the analysis of SPET and PET data may be based on ratios of activity between brain ROIs where uptake in the cerebellum or occipital cortex is held as reference (fig 7). This approach has the advantage of increasing the consistency of image interpretation more independently of reader experience than visual assessment. Most scanners have built in software that allows drawing of ROIs. Exporting digital images from the SPET/PET scanner to a peripheral workstation is an easy alternative.

$\mathrm{O}^{\prime}$ Brien et $\mathrm{a}^{59}$ found that regional cerebral blood flow assessed with SPET in anterior and posterior frontal, parietal,

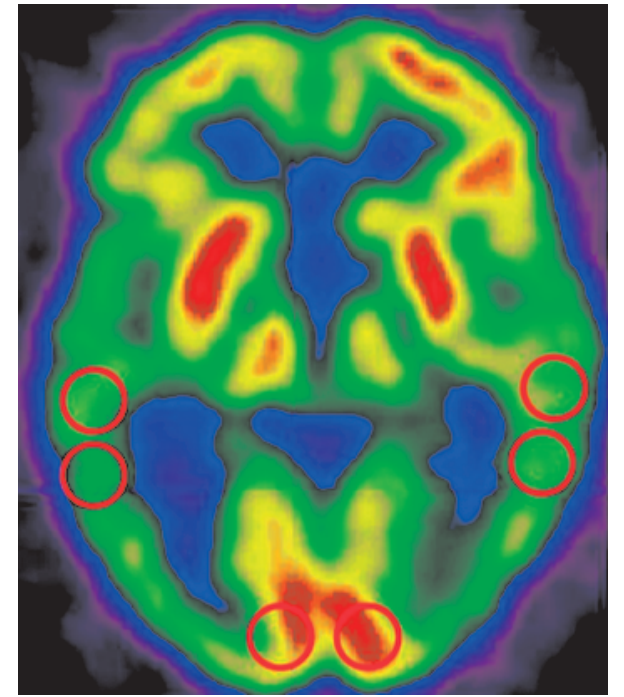

Figure 7 SPET/PET level 2: ROI sampling on digital ${ }^{18}$ FDG-PET. ROI are located in the temporoparietal (two ROls for each side) and occipital (one $\mathrm{ROI}$ for each side) regions. Metabolism in the parietal regions is computed as the ratio of tracer uptake in the parietal and occipital ROls.

occipital, and mesial temporal cortex using an ROI analysis with the cerebellum as a reference area was able to separate $30 \mathrm{AD}$ patients from 22 controls with $77 \%$ sensitivity and $82 \%$ specificity. In $30 \mathrm{MCI}$ patients, Okamura et $\mathrm{al}^{7}$ found that the ratio of a cerebrospinal fluid biomarker of $\mathrm{AD}$ ( tau protein) to posterior cingulate perfusion could identify those patients who progressed to $\mathrm{AD}$ with sensitivity of $88.5 \%$ and specificity of $90 \%$.

The issue of inter-individual variability is not fully resolved by this technique because the selection of ROIs depends on the observer's a priori choice and hypothesis, implying a preconception about the topography of the deficit. Moreover, the technique is time consuming if coverage of the entire brain volume by a large number of ROIs is required..$^{601}$

On the other hand, localisation of precise brain structures can be obtained on MRI and superimposed on co-registered PET image. Studies that combined functional and anatomical imaging have suggested that inter-group comparisons of regional metabolic values are diagnostically superior to volume measurements in AD. ${ }^{62}$ An MRI driven ROI analysis was used in a longitudinal study of initially normal elderly controls where glucose metabolism in the entorrhinal cortex was shown to predict cognitive decline to MCI or even to $\mathrm{AD}^{63}$

\section{SPET/PET LEVEL 3: VOXEL BY VOXEL ANALYSIS IN A STEREOTACTIC SPACE}

The recent development of computer assisted analysis provides objective and reliable assessment of functional brain abnormalities. This approach is a voxel by voxel analysis in a stereotactic space to avoid subjectivity and to adopt the principle of data driven analysis ${ }^{61}$ (fig 8).

Although voxel by voxel analysis in stereotactic space was not originally devised to analyse individual cases, Signorini et $a l^{60}$ have validated a protocol based on statistical parametric mapping (SPM) that allows estimation of functional defects in individual cases. The method gives a false positive rate of about $5 \%$ (specificity of $95 \%$ ) but the false negative rate (sensitivity) has not yet been satisfactorily addressed. It should be noted that the method requires a group of normative images taken with the same scanner in cognitively normal elderly controls. 


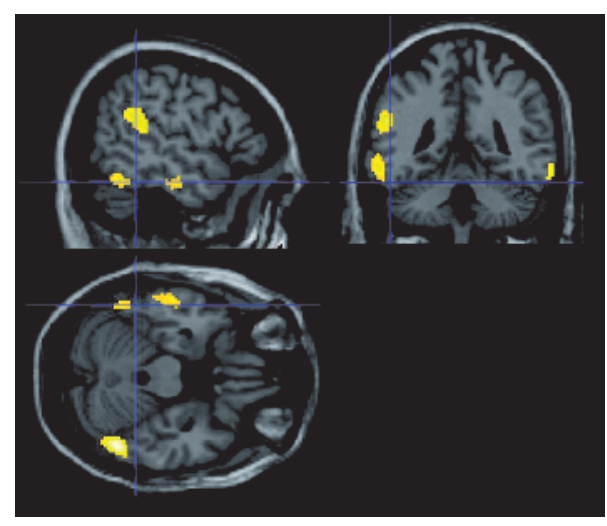

Figure 8 SPET/PET level 3: voxel based analysis of PET data showing metabolic decrease in a single $A D$ patient compared with 21 elderly controls. Significant metabolic impairment $(p<0.01)$ in superior and inferior temporal cortex is superimposed on a canonical MR picture.

Herholz et $a l^{64}$ showed in a study of 395 patients with AD and 110 controls that automated PET analysis with SPM reached $93 \%$ sensitivity and specificity in the distinction of mild to moderate AD from controls, and $84 \%$ sensitivity and 93\% specificity in the detection of very mild AD (MMSE $>24)$. With another voxel based method of analysis, a metabolic pattern similar to that observed in $\mathrm{AD}$ was reported in cognitively normal carriers of the apolipoprotein $\mathrm{E} \epsilon 4$ allele with a familial history of $\mathrm{AD}$, and a significant decline in glucose metabolism was observed over an interval of approximately 2 years. ${ }^{65}$ The authors have emphasised the availability of PET to test the efficacy of treatments for attenuating this metabolic decline.

The usefulness of these methods in the clinical routine is promising but there are yet no data on their added diagnostic value. ${ }^{65-67}$

\section{DISCUSSION}

The sophisticated clinical questions that modern physicians need to answer require equally sophisticated tools and methods. Patients with cognitive impairment have additional complexity in that the clinical picture may not be sufficiently characteristic, brain changes are subtle, and diagnosis and management would benefit from precise neuroimaging information. As outlined above, the dementia specialist has a wide range of options to extract quantitative information from neuroimaging examinations, which may assist in the positive diagnosis of dementia. Options range from tools with high feasibility that can be used at the patient's bedside to highly technological tools that require trained personnel and specific hardware and software. The quality of the obtained information is obviously different, although there are yet no indications as to which tool is more useful or has the highest cost/benefit ratio in clinical practice. The dementia specialist will thus need to match clinical requirements with technological demands and local opportunities.

A number of questions remain open that will deserve attention in the near future.

\section{The differential diagnosis of the dementias: detecting patterns of atrophy or brain functional impairment with computational imaging}

Imaging research of the last 10 years has led us to believe that the dementias have relatively specific imaging patterns. ${ }^{68}$ Although a detailed review is beyond the scope of this work and can be found elsewhere, ${ }^{15} 69$ a few key facts should be highlighted. Pick's disease often shows asymmetric anterior frontal and/or temporal atrophy of the cortex and white matter, with enlargement of the ventricular horns so severe that quantitative measures are superfluous. The frontal variant of frontotemporal degeneration shows more prominent frontal and temporal atrophy than $\mathrm{AD}$ but milder hippocampal atrophy. ${ }^{68}$ Dementia with Lewy bodies shows hippocampal atrophy milder than $\mathrm{AD}$, no occipital lobe atrophy, and occipital SPET hypoperfusion or PET hypometabolism. ${ }^{68} 7071$ The pattern of atrophy of Parkinson's disease with dementia is similar to $\mathrm{AD}^{39}{ }^{68}$ Vascular dementia features hippocampal atrophy less severe than $\mathrm{AD}$ in addition to cortical and/or subcortical signs of vascular damage. ${ }^{39} 68$ Although atrophy pattern detection might be useful diagnostic information, to date there is no single tool that allows detection of the patterns in a given patient, and the physician will need to compound two or more of the quantitative tools described in this paper. Newly developed computerised tools based on high resolution MR images such as voxel based morphometry $^{72}$ and cortical pattern matching ${ }^{73}$ allow unbiased assessment of atrophy and, with appropriate changes to make them suitable to single case analyses, ${ }^{74}$ might be the future answer.

\section{The clinical topographic correlates of subcortical cerebrovascular disease}

The high prevalence of subcortical cerebrovascular disease in patients with $\mathrm{AD}^{75}$ and its contribution to cognitive impairment $^{76}$ account for the development of many CT and MR based rating tools. ${ }^{18}$ However, these have failed to enter the clinical routine for at least two reasons. First, it is not clear to what extent some images (diffuse leukoaraiosis and patchy lesions on CT, and punctate and confluent hyperintensities on MR) denote vascular pathology. Although clinicopathological correlations are available ${ }^{77}$ more work is clearly needed. Secondly, the clinical correlates of subcortical cerebrovascular disease are unclear. WMH have been associated with cognitive impairment, ${ }^{78}$ parkinsonism, ${ }^{79}$ late life depression, ${ }^{80}$ and psychosis, ${ }^{81}$ but it is unclear why some patients develop one rather than another syndrome. Recently, Benson et a ${ }^{82}$ have used an automated segmentation method to separate pathological from normal white matter in 16 elderly subjects with and 12 without mobility impairment. With voxel based morphometry applied to WMH, they showed that frontal periventricular WMHswere sensitive (93\%) and parietooccipital WMH were specific (100\%) in detecting mobility impairment in this group of subjects. ${ }^{82}$ This or other computerised neuroanatomy techniques may help in better understanding the clinical correlates of WMH.

\section{The prediction of conversion of mild cognitive impairment to Alzheimer's disease}

Three parameters are the acknowledged predictors of the conversion of MCI to $\mathrm{AD}$, and two are based on imaging: low hippocampal volume, ${ }^{5}$ hypoperfusion of the temporoparietal cortex,${ }^{83}$ and elevated tau protein in the $\mathrm{CSF}^{8}{ }^{84}$ with decreased a-beta. ${ }^{84}$ However, none of the predictors taken alone seems to yield sufficiently satisfactory accuracy. For example, only $46 \%$ of MCI patients with severe hippocampal atrophy $(2.5$ SDs or more below the age specific mean) and 35\% of those with minimal to moderate atrophy (from 0 to 2.5 SDs below) have converted to $\mathrm{AD} 3$ years after baseline assessment. ${ }^{5}$ Compounding imaging and biological information to enhance the accuracy of the prediction seems a more promising strategy. Okamura et al $^{7}$ have studied $30 \mathrm{MCI}$ patients, 22 of whom had and eight did not have progression of the cognitive impairment in the following 3 years, and found that a high ratio between tau in the CSF and posterior cingulate perfusion on SPET could identify progressors with sensitivity of $89 \%$ and specificity of $90 \%$. Alternatively, compounding structural information on atrophy in more 
than one structure might enhance the predictive power (for a comprehensive review see Chetelat and Baron $^{85}$ ). Future studies will need to identify the most accurate and feasible combination of predictors of conversion.

\section{Probes for $\beta$-amyloid with PET/SPET}

The most promising area of research in functional imaging is the use of blood-brain barrier permeable radio probes specific for plaques, enabling SPECT or PET visualisation of these lesions in living $\mathrm{AD}$ patients. A variety of agents targeting abeta deposits have been developed ${ }^{86}{ }^{87}$ and studies in living patients have already begun. ${ }^{88} 89$ The difficulty in developing these tools lies in the need for the agents to cross the bloodbrain barrier while recognizing a-beta with high sensitivity and specificity. ${ }^{90}$

\section{Assessing the clinical usefulness of diagnostic imaging}

In most medical fields, the evidence to support the use of diagnostic tests is scarce, and cognitive neuroscience is no exception. Of the tools presented here, evidence of added diagnostic value (that is the diagnostic accuracy compared to current clinical accuracy for the diagnosis) was available for only two (visual rating of the medial temporal lobe on MR and visual rating of color coded hardcopies on SPET images). Ideally, any diagnostic test should pass four phases before entering clinical practice, aimed at answering the following questions:

- Do test results in patients with the target disorder differ from those in normal people? (phase I)

- Are patients with certain test results more likely to have the target disorder than patients with other test results? (phase II)

- Does the test result distinguish patients with and without the target disorder among patients in whom it is clinically reasonable to suspect that the disease is present? (phase III)

- Do patients who undergo this diagnostic test fare better (in their ultimate health outcomes) than similar patients who are not tested? (phase IV).

Diagnostic tests are usually supported by phase I, seldom by phase II and almost never by phase III and IV studies. ${ }^{91}$ As a consequence, tests are used based more on likelihood, extension, and analogy rather than direct evidence. ${ }^{92}$ One of the boldest challenges of the future will be to fill the gap between the rapid increase of diagnostic tools driven by technological developments and the collection of evidence of their clinical usefulness.

\section{ACKNOWLEDGEMENTS}

The following have contributed to the production of the first draft in Toulouse on November 12, 2001: D Chan (London, UK), B GomezAnson (Barcelona, Spain), P Payoux and T Voisin (Toulouse, France), and G Rodriguez (Genova, Italy). A Beltramello (Service of Neuroradiology, Ospedale Borgo Trento, Verona), N Purandare (School of Psychiatry and Behavioral Sciences, University of Manchester, UK), and the principal investigators of the EADC Centers (for the complete list see www.alzheimer-europe.org/eadc) critically revised the manuscript.

\section{Authors' affiliations}

G B Frisoni, S Galluzzi, Laboratory of Epidemiology \& Neuroimaging, IRCCS San Giovanni di Dio-FBF, Brescia, Italy

P h Scheltens, Alzheimer Center, Department of Cognitive Neurology, Vrije Universiteit Medical Center, Amsterdam, The Netherlands F M Nobili, Division of Clinical Neurophysiology, Department of Internal Medicine, University of Genoa, Italy

N C Fox, Dementia Research Group, Department of Clinical Neurology, Institute of Neurology, University College London, London, UK
P H Robert, Centre Memoire, Unite d'Evaluation des Cognitions, Hopital Pasteur, Centre Hospitalier Universitaire de Nice, France

H Soininen, Department of Neurology, Kuopio University Hospital, Kuopio, Finland

L-O Wahlund, Department of Clinical Neuroscience, NEUROTEC, Karolinska Institutet at Huddinge University Hospital, Huddinge, Sweden G Waldemar, Department of Neurology, Copenhagen University Hospital, Copenhagen, Denmark

E Salmon, Department of Neurology and Cyclotron Research Centre, University of Liege, Liege, Belgium

Competing interest: none declared

\section{REFERENCES}

1 Practice parameter for diagnosis and evaluation of dementia. Report of the Quality Standards Subcommittee of the American Academy of Neurology. Neurology 1994;44:2203-6.

2 Scheltens $P$, Fox $N$, Barkhof $F$, et al. Structural magnetic resonance imaging in the practical assessment of dementia: beyond exclusion. Lancet Neurol 2002;1:13-21.

3 Lopez OL, Becker JT, Klunk W, et al. Research evaluation and diagnosis of probable Alzheimer's disease over the last two decades: I. Neurology 2000;55:1854-62.

4 Lopez OL, Becker JT, Klunk W, et al. Research evaluation and diagnosis of possible Alzheimer's disease over the last two decades: II. Neurology 2000;55:1863-9.

5 Jack CR Jr, Petersen RC, Xu YC, et al. Prediction of AD with MRI-based hippocampal volume in mild cognitive impairment. Neurology 1999;52:1397-403.

6 Johnson KA, Jones K, Holman BL, et al. Precli imaging, cognitive impairment, Alzheimer, atrophy, cerebrovascular disease, rating scales. Nical prediction of Alzheimer's disease using SPECT. Neurology 1998;50:1563-71.

7 Okamura N, Arai H, Maruyama M, et al. Combined analysis of CSF tau levels and [(123)!]iodoamphetamine SPECT in mild cognitive impairment: implications for a novel predictor of Alzheimer's Disease. Am J Psychiatry 2002;159:474-6.

8 Chetelat G, Desgranges B, de la Sayette V, et al. Mild cognitive impairment: Can FDG-PET predict who is to rapidly convert to Alzheimer's disease? Neurology 2003;60:1374-7.

9 Fox NC, Cousens S, Scahill R, et al. Using serial registered brain magnetic resonance imaging to measure disease progression in Alzheimer disease: power calculations and estimates of sample size to detect treatment effects. Arch Neurol 2000;57:339-44.

10 Peripheral and Central Nervous System Drugs Advisory Committee. Joint Meeting with Medical Imaging Drugs Advisory Committee; November 18-19, 2002. http://www.fda.gov/ohrms/dockets/ac/cder02.htm\# PeripheralandCentralNervousSystemDrugs. Accessed May 23, 2003.

11 Roman GC, Tatemichi TK, Erkinjuntti T, et al. Vascular dementia: diagnostic criteria for research studies. Report of the NINDS-AIREN International Workshop. Neurology 1993;43:250-60.

12 Erkinjuntti T, Inzitari D, Pantoni L, et al. Research criteria for subcortical vascular dementia in clinical trials. J Neural Transm Suppl 2000;59:23-30.

13 Waldemar G, Dubois B, Emre M, et al. Diagnosis and management of Alzheimer's disease and other disorders associated with dementia. The role of neurologists in Europe. European Federation of Neurological Societies. Eur J Neurol 2000;7:133-44.

14 Knopman DS, DeKosky ST, Cummings JL, et al. Practice parameter: diagnosis of dementia (an evidence-based review). Report of the Quality Standards Subcommittee of the American Academy of Neurology. Neurology 2001;56:1143-53.

15 Bosscher L, Scheltens P. MRI of the medial temporal lobe for the diagnosis of Alzheimer's disease. In: Qizilbash N, ed. Evidence-based dementia practice. Oxford: Blackwell Science, 2002:154-62.

16 Goethals I, Van De Wiele C, Slosman D, et al. Brain SPET perfusion in early Alzheimer's disease: where to look? Eur J Nucl Med Mol Imaging 2002;29:975-8.

17 Holloway F. Outcome measurement in mental health-welcome to the revolution. Br J Psychiatry 2002;181:1-2.

18 Scheltens $\mathbf{P}$, Erkinjunti T, Leys $\mathrm{D}$, et al. White matter changes on $\mathrm{CT}$ and MRI: an overview of visual rating scales. European Task Force on Age-Related White Matter Changes. Eur J Neurol 1998;39:80-9.

19 Ashburner J, Csernansky JG, Davatzikos C, et al. Computer-assisted imaging to assess brain structure in healthy and diseased brains. Lancet Neurol 2003;2:79-88.

20 Salmon E. Functional brain imaging applications to differential diagnosis in the dementias. Curr Opin Neurol 2002; 15:439-44.

21 Wahlund LO, Barkhof F, Fazekas F, et al. European Task Force on AgeRelated White Matter Changes: A new rating scale for age-related white matter changes applicable to MRI and CT. Stroke 2001;32:1318-22.

22 Jobst KA, Smith AD, Szatmari M, et al. Detection in life of confirmed Alzheimer's disease using a simple measurement of medial temporal lobe atrophy by computed tomography. Lancet 1992;340:1179-83.

23 Gao FQ, Black SE, Leibovitch FS, et al. A reliable MR measurement of medial temporal lobe width from the Sunnybrook Dementia Study. Neurobiol Aging 2003;24:49-56.

24 Frisoni GB, Beltramello A, Weiss $C$, et al. Linear measures of atrophy in mild Alzheimer disease. Am J Neuroradiol 1996;17:913-23. 
25 Denihan A, Wilson G, Cunningham C, et al. CT measurement of medial temporal lobe atrophy in Alzheimer's disease, vascular dementia, depression and paraphrenia. Int J Geriatr Psychiatry 2000;15:306-12.

26 Jobst KA, Smith AD, Szatmari M, et al. Rapidly progressing atrophy of medial temporal lobe in Alzheimer's disease. Lancet 1994:343:829-30.

27 Frisoni GB, Geroldi C, Beltramello A, et al. Radial width of the temporal horn: a sensitive measure in Alzheimer disease. Am J Neuroradiol 2002;23:35-47.

28 Laakso MP, Frisoni GB, Kononen M, et al. Hippocampus and entorhinal cortex in frontotemporal dementia. A qualitative MRI study. Biol Psychiatry 2000;47:1056-63.

29 Frisoni GB, Rossi R, Beltramello A. The radial width of the temporal horn in mild cognitive impairment. J Neuroimaging 2002;12:351-4.

30 Scheltens $\mathrm{P}$, Leys $\mathrm{D}$, Barkhof $\mathrm{F}$, et al. Atrophy of medial temporal lobes on MRI in "probable" Alzheimer's disease and normal ageing: diagnostic value and neuropsychological correlates. I Neurol Neurosurg Psychiatry 1992;55:967-72.

31 Wahlund LO, Julin P, Johansson SE, et al. Visual rating and volumetry of the medial temporal lobe on magnetic resonance imaging in dementia: a comparative study. J Neurol Neurosurg Psychiatry 2000;69:630-5.

32 Visser PJ, Verhey FR, Hofman PA, et al. Medial temporal lobe atrophy predicts Alzheimer's disease in patients with minor cognitive impairment. J Neurol Neurosurg Psychiatry 2002;72:491-7.

33 Rockwood K, Parhad I, Hachinski V, et al. Diagnosis of vascular dementia: Consortium of Canadian Centres for Clinical Cognitive Research concensus statement. Can J Neurol Sci 1994;21:358-64.

34 Lopez OL, Becker JT, Jungreis CA, et al. Computed tomography-but not magnetic resonance imaging-identified periventricular white-matter lesions predict symptomatic cerebrovascular disease in probable Alzheimer's disease. Arch Neurol 1995;52:659-64.

35 Pantoni L, Leys D, Fazekas F, et al. Role of white matter lesions in cognitive impairment of vascular origin. Alzheimer Dis Assoc Disord 1999;13(Suppl 3):S49-54.

36 Frisoni GB, Padovani A, Wahlund LO. The diagnosis of Alzheimer's disease before it is Alzheimer's dementia. Arch Neurol 2003, in press.

37 Du AT, Schuff N, Amend D, et al. Magnetic resonance imaging of the entorhinal cortex and hippocampus in mild cognitive impairment and Alzheimer's disease. J Neurol Neurosurg Psychiatry 2001;71:441-7.

38 Jack CR Jr, Bentley MD, Twomey CK, et al. MR imaging-based volume measurements of the hippocampal formation and anterior temporal lobe: validation studies. Radiology 1990;176:205-9.

39 Laakso MP, Partanen $\mathrm{K}$, Riekkinen $\mathrm{P}$, et al. Hippocampal volumes in Alzheimer's disease, Parkinson's disease with and without dementia, and in vascular dementia: An MRI study. Neurology 1996;46:678-81.

40 Laakso MP, Soininen H, Partanen K, et al. MRI of the hippocampus in Alzheimer's disease: sensitivity, specificity, and analysis of the incorrectly classified subjects. Neurobiol Aging 1998;19:23-31.

41 DeCarli C, Maisog J, Murphy DG, et al. Method for quantification of brain, ventricular, and subarachnoid CSF volumes from MR images. J Comput Assist Tomogr 1992;16:274-84.

$42 \mathrm{Ge} \mathrm{Y,} \mathrm{Grossman} \mathrm{RI,} \mathrm{Babb} \mathrm{JS,} \mathrm{et} \mathrm{al.} \mathrm{Age-related} \mathrm{total} \mathrm{gray} \mathrm{matter} \mathrm{and} \mathrm{white}$ matter changes in normal adult brain. Part I: volumetric MR imaging analysis, AJNR Am J Neuroradiol 2002;23:1327-33.

43 Smith SM, Zhang $Y$, Jenkinson $M$, et al. Accurate, robust, and automated longitudinal and cross-sectional brain change analysis. Neuroimage 2002:17:479-89

44 DeCarli C, Miller BL, Swan GE, et al. Cerebrovascular and brain morphologic correlates of mild cognitive impairment in the National Heart, Lung, and Blood Institute Twin Study. Arch Neurol 2001:58:643-7.

45 Fox NC, Freeborough PA, Rossor MN. Visualisation and quantification of rates of atrophy in Alzheimer's disease. Lancet 1996;348:94-7.

46 Chan D, Fox NC, Jenkins R, et al. Rates of global and regional cerebral atrophy in AD and frontotemporal dementia. Neurology 2001;57:1756-63.

47 Fox NC, Freeborough PA. Brain atrophy progression measured from registered serial MRI: validation and application to Alzheimer's disease. $J$ Magn Reson Imaging 1997;7:1069-75.

48 Fox NC, Scahill RI, Crum WR, et al. Correlation between rates of brain atrophy and cognitive decline in AD. Neurology 1999:52:1687-9.

49 Fox NC, Warrington EK, Freeborough PA, et al. Presymptomatic hippocampal atrophy in Alzheimer's disease. A longitudinal MRI study. Brain 1996;1 19:2001-7

50 Fox NC, Crum WR, Scahill Rl, et al. Imaging of onset and progression of Alzheimer's disease with voxel-compression mapping of serial magnetic resonance images. Lancet $2001 ; 358: 201-5$.

51 Perani D. The role of emission tomography in dementia. Ital J Neurol Sci 1999;20(Suppl 5):S254-7

52 Messa C, Perani D, Lucignani G, et al. High-resolution technetium-99mHMPAO SPECT in patients with probable Alzheimer's disease: comparison with fluorine-18-FDG PET. J Nud Med 1994;35:210-16.

53 Waldemar G, Bruhn P, Kristensen M, et al. Heterogeneity of neocortical cerebral blood flow deficits in dementia of the Alzheimer type: a [99mTc]-d,lHMPAO SPECT study. J Neurol Neurosurg Psychiatry 1994:57:285-95.

54 Jagust W, Thisted R, Devous MD Sr, et al. SPECT perfusion imaging in the diagnosis of Alzheimer's disease: a clinical-pathologic study. Neurology 2001;56:950-6.

55 Pearlson GD, Harris GJ, Powers RE, et al. Quantitative changes in mesial temporal volume, regional cerebral blood flow, and cognition in Alzheimer's disease. Arch Gen Psychiatry 1992;49:402-8.

56 Jobst KA, Smith AD, Barker CS, et al. Association of atrophy of the medial temporal lobe with reduced blood flow in the posterior parietotemporal cortex in patients with a clinical and pathological diagnosis of Alzheimer's disease. J Neurol Neurosurg Psychiatry 1992;55:190-4.
57 Scheltens $\mathbf{P}$, Launer $\sqcup$, Barkhof $F$, et al. The diagnostic value of magnetic resonance imaging and technetium $99 \mathrm{~m}$-HMPAO single-photon-emission computed tomography for the diagnosis of Alzheimer disease in a communitydwelling elderly population. Alzheimer Dis Assoc Disord 1997;11:63-70.

58 Silverman DH, Small GW, Chang CY, et al. Positron emission tomography in evaluation of dementia: Regional brain metabolism and long-term outcome. JAMA 2001;286:2120-7

59 O'Brien JT, Ames D, Desmond P, et al. Combined magnetic resonance imaging and single-photon emission tomography scanning in the discrimination of Alzheimer's disease from age-matched controls. Int Psychogeriatr 2001;13:149-61.

60 Signorini M, Paulesu E, Friston K, et al. Rapid assessment of regional cerebral metabolic abnormalities in single subjects with quantitative and nonquantitative [18F]FDG PET: A clinical validation of statistical parametric mapping. Neuroimage 1999;9:63-80.

61 Matsuda H. Cerebral blood flow and metabolic abnormalities in Alzheimer's disease. Ann Nucl Med 2001;15:85-92.

62 De Santi S, de Leon MJ, Rusinek $\mathrm{H}$, et al. Hippocampal formation glucose metabolism and volume losses in $\mathrm{MCl}$ and $\mathrm{AD}$. Neurobiol Aging 2001;22:529-39.

63 de Leon MJ, Convit A, Wolf OT, et al. Prediction of cognitive decline in normal elderly subjects with 2-[(18)F]fluoro-2-deoxy-D-glucose/positronemission tomography (FDG/PET). Proc Natl Acad Sci USA $2001 ; 98: 10966-71$.

64 Herholz K, Salmon E, Perani D, et al. Discrimination between Alzheimer dementia and controls by automated analysis of multicenter FDG PET. Neuroimage 2002;17:302-16.

65 Reiman EM, Caselli RJ, Chen K, et al. Declining brain activity in cognitively normal apolipoprotein $\mathrm{E}$ epsilon 4 heterozygotes: A foundation for using positron emission tomography to efficiently test treatments to preven Alzheimer's disease. Proc Natl Acad Sci USA 2001;98:3334-9.

66 Van Laere KJ, Warwick J, Versijpt J, et al. Analysis of clinical brain SPECT data based on anatomic standardization and reference to normal data: an ROC-based comparison of visual, semiquantitative, and voxel-based methods. J Nucl Med 2002:43:458-69.

67 Nobili F, Koulibaly M, Vitali P, et al. Brain perfusion follow-up in Alzheimer's patients during treatment with acetylcholinesterase inhibitors. J Nucl Med 2002;43:983-90.

68 Frisoni GB. Structural imaging in the clinical diagnosis of Alzheimer's disease: problems and tools. J Neurol Neurosurg Psychiatry 2001;70:711-18.

69 Fontaine S, Bourgouin P. Structural brain imaging in Alzheimer's disease. In: Gauthier S, ed. Clinical diagnosis and management of Alzheimer's disease. London: Martin Dunitz, 1999:107-16.

70 Lobotesis K, Fenwick JD, Phipps A, et al. Occipital hypoperfusion on SPECT in dementia with Lewy bodies but not AD. Neurology 2001;56:643-9.

71 Middelkoop HA, van der Flier WM, Burton EJ, et al. Dementia with Lewy bodies and $A D$ are not associated with occipital lobe atrophy on MRI. Neurology 2001;57:2117-20.

72 Ashburner J, Friston KJ. Voxel-based morphometry - the methods. Neuroimage 2000;14:805-21.

73 Thompson PM, Mega MS, Toga AW. Disease-specific brain atlases. In: Toga AW, Mazziotta JC, eds. Brain mapping: the disorders. Academic Press, 2000:131-77.

74 Woermann FG, Free SL, Koepp MJ, Ashburner J, ef al. Voxel-by-voxe comparison of automatically segmented cerebral gray matter-a raterindependent comparison of structural MRI in patients with epilepsy. Neurolmage 1999; 10:373-84

75 Neuropathology Group. Medical Research Council Cognitive Function and Aging Study. Pathological correlates of late-onset dementia in a multicentre, community-based population in England and Wales. Neuropathology Group of the Medical Research Council Cognitive Function and Ageing Study (MRC CFAS). Lancet 2001;357:169-75.

76 Snowdon DA, Greiner LH, Mortimer JA, et al. Brain infarction and the clinical expression of Alzheimer disease. The Nun Study. JAMA 1997:277:813-7.

77 Fazekas $\mathrm{F}$, Kleinert $\mathrm{R}$, Offenbacher $\mathrm{H}$, et al. Pathologic correlates of incidental MRI white matter signal hyperintensities. Neurology 1993;43:1683-9.

78 DeCarli C, Murphy DG, Tranh M, et al. The effect of white matter hyperintensity volume on brain structure, cognitive performance, and cerebra metabolism of glucose in 51 healthy adults. Neurology 1995;45: 2077-84.

79 Zijlmans JC, Thijssen $\mathrm{HO}$, Vogels OJ, et al. MRI in patients with suspected vascular parkinsonism. Neurology 1995:45:2183-8.

80 O'Brien J, Ames D, Chiu E, et al. Severe deep white matter lesions and outcome in elderly patients with major depressive disorder: follow up study. BMJ 1998;317:982-4.

81 Tonkonogy JM, Geller JL. Late-onset paranoid psychosis as a distinct clinicopathologic entity: magnetic resonance imaging data in elderly patients with paranoid psychosis of late onset and schizophrenia of early onset. Neuropsychiatry Neuropsychol Behav Neurol 1999;12:230-5.

82 Benson RR, Guttmann CR, Wei X, et al. Older people with impaired mobility have specific loci of periventricular abnormality on MRI. Neurology 2002; 58:48-55

83 Arnaiz E, Jelic V, Almkvist $\mathrm{O}$, et al. Impaired cerebral glucose metabolism and cognitive functioning predict deterioration in mild cognitive impairment. Neuroreport $2001 ; 12: 851-5$

84 Riemenschneider M, Lautenschlager N, Wagenpfeil S, et al. Cerebrospinal fluid tau and beta-amyloid 42 proteins identify Alzheimer disease in subjects with mild cognitive impairment. Arch Neurol 2002;59:1729-34.

85 Chetelat G, Baron J-C. Early diagnosis of Alzheimer's disease: contribution of structural neuroimaging. Neurolmage 2003;18:525-41. 
86 Klunk WE, Wang Y Huang GF, et al. The binding of 2-(4' methylaminophenyl)benzothiazole to postmortem brain homogenates is dominated by the amyloid component. J Neurosci 2003;23:2086-92.

87 Skovronsky DM, Zhang B, Kung MP, et al. In vivo detection of amyloid plaques in a mouse model of Alzheimer's disease. Proc Natl Acad Sci USA 2000;97:7609-14

88 Shoghi-Jadid K, Small GW, Agdeppa ED, et al. Localization of neurofibrillary tangles and beta-amyloid plaques in the brains of living patients with Alzheimer disease. Am J Geriatr Psychiatry 2002;10:24-35.
89 Petrella JR, Coleman RE, Doraiswamy PM. Neuroimaging and early diagnosis of Alzheimer disease: a look to the future. Radiology 2003;226:315-36.

90 Small GW, Agdeppa ED, Kepe V, et al. In vivo brain imaging of tangle burden in humans. J Mol Neurosci 2002;19:323-7.

91 Sackett DL, Haynes RB. The architecture of diagnostic research. BMJ 2002;324:539-41.

92 Hillman BJ. Medical imaging in the 21 st century. Lancet 1997;350: 731-3.

\section{NEURONLINE}

\section{Clinical neurophysiology on the internet: www.neurophys.com}

S traightforwardly, this website, www.neurophys.com pitches itself as "clinical neurophysiology on the internet". It does indeed cover the spectrum of neurophysiology from basic science to neurophysiology on through to clinical practice; however, there is clearly more of an emphasis on the physiology of the nervous system than on what we now accept as the realm of

clinical neurophysiology and its quantitative analysis of the nervous system.

There is some useful coverage of fundamental neurophysiological principles and neuroanatomy and its functional components with concise text and clear diagrammatic representations. This is helpful from an educational point of view and providing a refresher of those neural pathways that you know

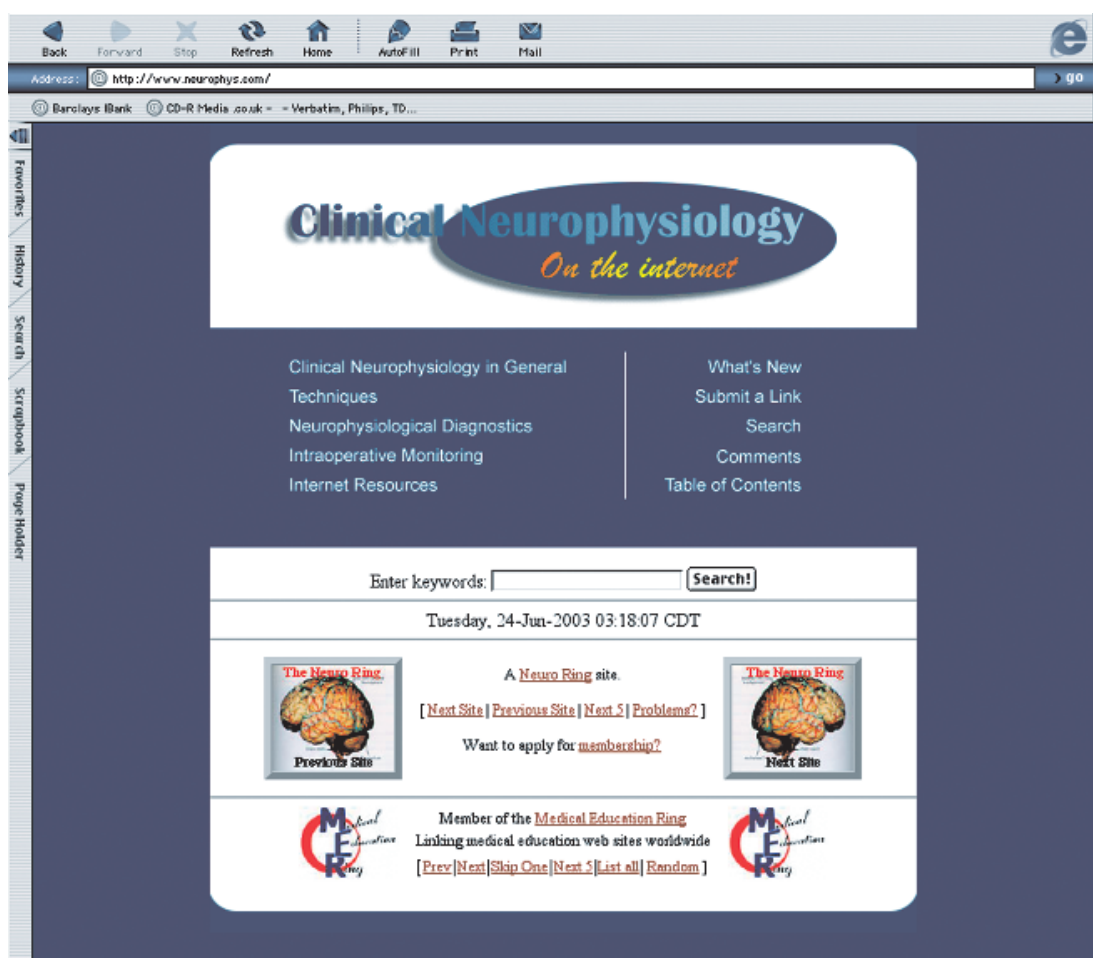

you should know. There are many useful links to the relevant neurophysiological organisations, institutions, and journals. This site, however, appears to rely on the array of various links rather than on its own intrinsic content.

There is an attempt at comprehensive coverage of EEG, EMG, and evoked potentials, but overall the depth of information available is limited. Use of the search engine for such topics as alpha coma and neuromyotonia was also disappointing.

The basic requirements of a good and useful site are its design and layout, allowing easy use and retaining the user's focus while also providing thorough coverage of the subject matter. On both counts I found this site somewhat lacking. The graphics are dated and some interactive content would be helpful. There are also an annoying number of broken links. The information available is limited, with whole areas, such as intraoperative monitoring and sleep, receiving scant attention.

Overall I found the site of limited interest. The positive aspects being in neurophysiological theory rather than its treatment of clinical matters of practical interest and concern to the clinical neurophysiologist or neurologist.

R MacDonagh

Department of Clinical Neurophysiology, Leeds General Infirmary, Leeds LS17 8TP, UK; rmacdonagh@hotmail.com 